\section{Direct-to-consumer advertising of psychotropics}

\author{
An emerging and evolving form of pharmaceutical company \\ influence
}

SIMON GILBODY, PAUL WILSON and IAN WATT

\section{ARGUMENTS FOR AND AGAINST}

Proponents of direct-to-consumer advertising claim that advertisements are a legitimate source of quality patient information (Bonaccorso \& Sturchio, 2002). Informing and empowering patients are major themes in the new National Health Service. In psychiatry, the treatments offered have both benefits and side-effects, and rational decisions regarding concordance might be enhanced through information targeted at patients. Additionally, many individuals do not seek help for psychiatric conditions, either through stigma or poor knowledge about illness or effective treatments. Direct-to-consumer advertising might therefore help to address unmet needs.

Arguments against direct-to-consumer advertising principally centre on concerns about the pharmaceutical industry's ability to produce unbiased information. Given the nature of market economics, the primary aim of advertising campaigns is to increase market share and profit, rather than enhance well-being (Findlay, 2001; Wolfe, 2002). Hence, advertisements may not look at all treatment options, including non-drug treatments, or provide a consumer with comprehensive information on potential adverse effects. Concerns about the quality of information in advertisements are justified, with one in four products violating US Food and Drug Administration regulations (Aitken \& Holt, 2000).

Hoffman \& Wilkes (1999), reflecting on the experience in the USA, assert that direct-to-consumer advertising

unreasonably increases consumer expectations, forces doctors to spend time disabusing patients of misinformation, diminishes the doctorpatient relationship because a doctor refuses to prescribe an advertised drug, or results in poor practice if the doctor capitulates and prescribes an inappropriate agent'.

Research evidence tends to support this assertion. Mintzes et al (2001) have compared prescribing patterns and consultations in Canada (where direct-toconsumer advertising is banned) and the USA (where it is well established). They showed that in the USA patients often requested drugs that were promoted through direct-to-consumer advertising and that clinicians were likely to acquiesce to these requests, despite feeling at best 'ambivalent' about the drug. No empirical research has ever demonstrated better communication and improved health outcomes. Direct-toconsumer advertising therefore undermines efforts to improve the efficiency gained from finite health budgets through costconscious guidelines and the use of generic drugs where branded drugs confer marginal benefit.

\section{DIRECT-TO-CONSUMER ADVERTISING OF PSYCHOTROPICS}

Psychotropics are heavily marketed, with paroxetine being the fourth most advertised of all prescription-only medicines - at a cost of US\$91.8 million in direct-toconsumer advertising alone (National Institute of Health Care Management, 2001). Direct-to-consumer advertising has increased disproportionately among psychotropics, with expensive magazine advertisements and television commercials. A few examples of specific campaigns give some insight into what we might expect from direct-to-consumer advertising.

In 1997, Eli Lilly began a US\$1520 million print advertising campaign in major magazines for fluoxetine (Prozac). Their advertising text played on negative public perceptions of benzodiazepines, while reassuring readers that Prozac is more innocuous: 'It's not a tranquilizer: It won't take away your personality. Depression can do that, but Prozac can't'. Non-drug treatments were presented as a secondary measure for use after a patient had begun to respond to fluoxetine, rather than as a genuine alternative (source: Advertisement for Prozac. Cosmopolitan, US edition, September 1997). Other campaigns have specifically targeted the use of generic drugs and the risk of 'generic substitution', asking patients to insist on a specific drug 'by name'.

\section{ADVERTISING, PATIENT EDUCATION AND PATIENT CARE - BLURRING THE BOUNDARIES}

The Association of British Pharmaceutical Industries (ABPI) has reformulated the advertising pose for psychiatry? 
arguments against direct-to-consumer advertising by claiming that they oppose advertising and instead present direct-toconsumer communication as a legitimate form of 'patient education'.

'Anyone else can supply information about medicines to patients - but those who know most about them, the pharmaceutical companies, are forbidden by law from doing so. .. . This form of censorship is outdated, and it is high time it was abolished' (ABPI Press Release 23 October 2002, www.abpi.org.uk/press/press\%20releases 02/021023.asp).

What might we expect in psychiatry when the boundaries between patient education, advertisement and patient care become blurred? Some examples should make us concerned.

The advent of patient information groups and the ready access that they provide to consumers has been harnessed by the pharmaceutical industry. Marc Czarka, a director for Eli Lilly in the Benelux, said in 1997 that Lilly funds the American Psychiatric Association and it sponsors and helped to create the Belgian League of Depression in 1995. 'It's useful for us because, unlike American law, European law does not allow us to talk directly to potential patients....The league does it for us' (cited in Thomson, 1997). Examples of more direct influence over individual patient care have also been seen in the USA. Janssen-Cilag has developed a programme of information leaflets, telephone support and crisis intervention, but only to those in receipt of their product, risperidone. The 'person to person' programme was launched, with a good deal of support from both the largest US patient representative group (the National Alliance for the Mentally Ill) and the American Psychiatric Association. In the UK, a similar collaborative initiative exists with the National Institute of Mental Health's ' 1 in 100' campaign, which is dedicated to helping 'people with schizophrenia, their families and friends' (ABPI, 2002).

One widely publicised development in quasi-direct-to-consumer advertising has been 'celebrity endorsement'. Ricky Williams, an American football player, regularly appears on television to discuss his 'social anxiety disorder', while being paid by GlaxoSmithKline to publicise their product, paroxetine. In an industry website, Williams says: 'It's amazing at how much I've grown and how much I've changed and how much I went through. And of course I owe a lot of that to Janey, my

SIMON GILBODY, DPhil, Academic Unit of Psychiatry, University of Leeds; PAUL WILSON, BA, Centre for Reviews and Dissemination, University of York; IAN WATT, FFPHM, Department of Health Sciences, University of York, UK

Correspondence: Simon Gilbody, Academic Unit of Psychiatry, I5 Hyde Terrace, University of Leeds, Leeds LS2 9JT, UK. E-mail: s.m.gilbody@leeds.ac.uk

(First received I5 October 2003, final revision 12 January 2004, accepted 2 February 2004)

therapist, and Paxil [US brand name for paroxetine]' (source: GlaxoSmithKline website http://www.paxil.com/sad/sa ricky_Q1.html, accessed 10 March 2003). The website also provides consumers with a social anxiety disorder test, with the encouragement to consult a professional following a positive score.

\section{WHAT IS TO BE DONE?}

Direct-to-consumer advertising exploits an information void that has been left by clinicians, health care providers and policy makers. Creating more informed patients is an aspiration with which no reasonable clinician can argue. This is especially needed in psychiatry, where stigma and misconceptions about the value of drug treatments contribute to poor compliance or prevent patients from seeking help. Whether formal or informal direct-to-consumer advertising fills this void with unbiased information is far from clear. In fact the opposite is likely to be true. Canada, which despite its geographical proximity to the USA has thus far resisted formal direct-to-consumer advertising, has funded research into the costs and consequences of such advertising. Mintzes, the author of this work, concluded:

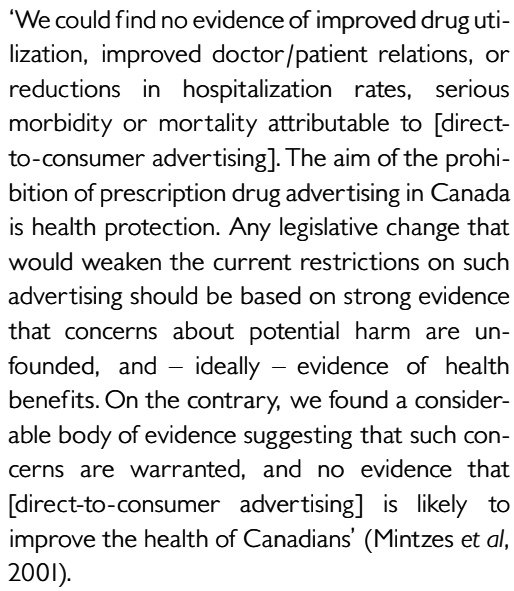

Sidney Wolfe, a clinician and director of the Public Citizen Health Research Group, writing in the New England Journal of Medicine said 'The education of patients - or physicians - is too important to be left to the pharmaceutical industry'. Wolfe called on the National Institutes of Health and the US Food and Drug Administration to "replace tainted drug company "education" with scientifically based, useful information that will stimulate better conversations between doctors and patients and lead to true empowerment' (Wolfe, 2002).

We believe that the advent of direct-toconsumer advertising should not be seen as progress. Psychiatry is likely to be changed for the worse and patient care is likely to be compromised as a consequence. There remains an onus on us all to strive to produce more informed patients and to provide unbiased information that is understandable and informative for those who require our care.

\section{DECLARATION OF INTEREST}

None.

\section{REFERENCES}

Aitken, M. \& Holt, F. (2000) A prescription for direct drug marketing. McKinsey Quarterly, 22 March, 82.

Association of British Pharmaceutical Industries (2002) ABPI Annual Review 2002. London: ABPI.

Bonaccorso, S. N. \& Sturchio, J. L. (2002) For and against: direct to consumer advertising is medicalising normal human experience: against. BMJ, 324, 910-91।.

Findlay, S. D. (200I) Direct-to-consumer promotion of prescription drugs: economic implications for patients, payers and providers. Pharmacoeconomics, 19, 109-119.

Hoffman, J. R. \& Wilkes, M. (1999) Direct to consumer advertising of prescription drugs. BMJ, $\mathbf{3 1 8}$, |30|-1302.

Leacock, S. (1924) The Garden of Folly. New York: Dodd Mead

Mintzes, B., Barer, M. L., Bassett, K., et al (200I) An Assessment of the Health System Impacts of Direct-toConsumer Advertising of Prescription Medicines (DTCA). Volume III: Patient Information on Medicines Comparative Patient/Doctor Survey in Vancouver and Sacramento. Vancouver: University of British Columbia Health Policy Research Unit.

National Institute of Health Care Management (200I) Prescription Drugs and Mass Media Advertising 2000. Washington, DC: NIHCM.

Thomson, C. (1997) Woke up this morning feelin' so blue. Took an antidepressant but what'll it do? Bulletin, 5 June, 24-3I.

Wolfe, S. M. (2002) Direct-to-consumer advertising education or emotion promotion? New England Journal of Medicine, 346, 524-526. 